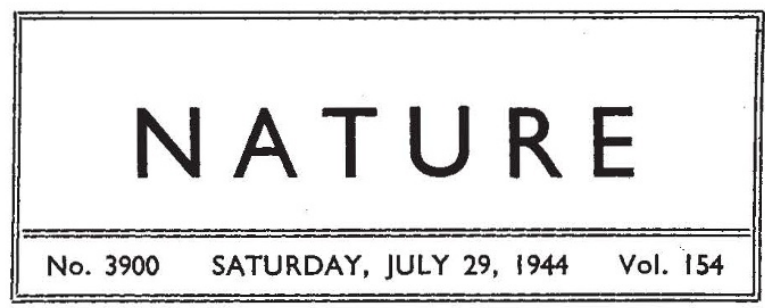

\title{
CONTENTS
}

Veterinary Education in Great Britain

Page

The Supremacy of Reason. By R. Brightman . . 129

Fourier Series. By J. H. Pearce . . . . I30

Australian Orchids. By Prof. E. J. Salisbury, C.B.E., F.R.S.

William Gilbert and the Science of his Time. By Prof. Sydney Chapman, F.R.S.

William Gilbert: His Place in the Medical World. By

Sir Walter Langdon-Brown . . . .

Cereal Diseases. By W. C. Moore . . . .

News and Views

Letters to the Editors:

Marine Biological Research in Great Britain.Prof. F. E. Fritsch, F.R.S.

Self-recovery in Metals.-Helen D. Megaw, Dr. H. Lipson and Dr. A. R. Stokes

Energy of Viscosity as a Measure of the Cohesion of Liquids.-L. Grunberg and Dr. A. H. Nissan .

Existence of Time-Dependence for Interfacial Tension of Solutions.-Dr. A. F. H. Ward and L. Tordai

Light-Effect in Chlorine under Electrical Discharge: Change of the Wave Form due to IrradiationProf. S. S. Joshi

Lanosterol.-Dr. C. Dorée and J. F. McGhie

Mitochondrial Origin of Cytosiderin (Iron Pigment) in the Liver of Human Pellagrins.-Dr. Theodore Gillman and Dr. Joseph Gillman

Rhythmic Changes in the Rat Produced by a Single Injection of Chloroform.-Phyllis Knocker and Joel Mandelstam .

'Fluorine-like' Action of Various Substances on the Teeth.-Prof. J. T. Irving

Artificial Production of Monstrosities in the Rabbit.-Dr. M. C. Chang

Wöhler's Work on Urea.-Dr. P. Mendelssohn Bartholdy ; Prof. J. Kenner, F.R.S. ; Dr. Douglas McKie

The Cedar Tree.-Dr. E. Weil

Research Items

Stimulation of the Anterior Hypophysis by Estrogenic Hormone. By Prof. Bernhard Zondek

The Scientific Outlook and its Presentation by Films. By Geoffrey Bell .

The Maxwell Laboratory at the University of Moscow.

By Prof. V. Arkadiev

Axis Orientation of Quartz Crystals .

Recent Scientific and Technical Books

Editorial and Publishing Offices

MACMILLAN \& CO., LTD.,

ST. MARTIN'S STREET, LONDON, W.C.2.

Telephone Number: Whitehall 8831

Telegrams: Phusis Lesquare London

Advertisements should be oddressed to

T. G. Scott \& Son, Ltd., Talbot House, 9 Arundel Street, London, W.C.2 Telephone : Temple Bar 1942

The annual subscription rate is $£ 4100$, payable in advance, Inland or Abroad. All rights reserved. Registered as a Newspaper at the General Post Office

\section{VETERINARY EDUCATION IN GREAT BRITAIN}

TN a leading article in Nature of January 8, 1944, the existing constitution and powers of the Royal College of Veterinary Surgeons, and the system of training and examination of British veterinarians was outlined. The key position of the veterinarian in the future, invested, as he must be, with the care of animals upon which our meat, egg and milk supplies depend, was then emphasized, and the interdependence of veterinary medicine and the agriculture from which we derive other vital food supplies was also pointed out. The desirability of a much closer association between the veterinary and the medical professions was also discussed. In the same issue of Nature, reference was made to a paper by Major J. M. Smith, in which he made very clear the vital part played by the veterinarian in the affairs of the British Colonies.

A Committee on Veterinary Education in Great Britain was appointed in 1936 by the Government, and issued its first report in 1938. In 1943 the same Committee was asked to reconsider its first recommendations, because, as the Minister of Agriculture wrote to Dr. T. Loveday, vice-chancellor of the University of Bristol, who is its chairman, there have been since 1938 great changes in the position and prospects of agriculture in Great Britain. The Government, wrote Mr. Hudson, intends to maintain after the War a healthy and well-balanced agriculture as an essential and permanent feature of its national policy ; and livestock, especially dairy herds, will need adequate care. The best possible training for the veterinarian of the future, continued Mr. Hudson, is therefore of vital importance to agriculture, and substantially greater numbers of veterinarians will be required. The Committee has in consequence met again, and its second report has now been issued (London: H.M. Stationery Office, $\epsilon d$. net), and will presumably go befere Parliament for discussion.

The Committee emphasizes that its revised recommendations are intended to secure, not merely. arf efficient system of training for the veterinarian, but also what it considers to be the best possible training. It also emphasizes that the revised recommendations are based on the assumption that British agriculture will, in fact, be maintained in a healthy and prosperous condition, "and will not be allowed to fall back into the state of uncertainty and depression which progressively prevailed between 1920 and 1939". The revised recommendations do not supersede those of the Committee's first report, except in certain important and possibly controversial particulars ; and the main conclusions of the first report are printed in Appendix I for comparison. A point strongly emphasized by the Committee is the urgent need for inquiry into the growing evil of unqualified veterinary practice, a recommendation to which effect has just been given (Nature, July 22, p. 111).

There should not be-indeed, there is not-in the mind of anyone who has given even a thought to the cost of animal disease in Great Britain alone, any doubt of the need for veterinarians, or of the financial 
saving which expansion of their work could effect. Appendix III of the report gives details of the national loss due to various diseases of farm livestock. The Cormmittee estimates that the total cost to the nation is not less than thirty million pounds a year, and rightly considers that the bulk of this loss is preventable, but only if much more money is spent on veterinary training.

Dealing with the future demand for veterinarians, the Committee revises its earlier estimate that about 150 veterinarians would be required annually between 1938 and 1942 and 115 afterwards. Actually 571 veterinarians qualified in the years 1940, 1941 and 1942, without causing unemployment in the profession. The Ministry of Agriculture and Fisheries, bearing in mind its plans for the future expansion of the State veterinary service and the Government's use of the services of private veterinary practitioners, now estimates a demand for 220 veterinarians a year for about ten years, with a possible reduction to $150 \mathrm{a}$ year later. The reasons given by the Committee for the increasing demand for veterinarians are the increasing appreciation by the farmer and the public that the veterinarian is the guarantor of the nation's food supply; the fact that the Government seems to be aiming at a quarterly examination by veterinarians of every dairy herd in the country (it is estimated that about $2 \frac{1}{2}$ million dairy cattle, which is about 80 per cent of all the dairy cattle in Great Britain at present, get no regular veterinary supervision); extension of veterinary supervision of meat production and of its control on the way to the market; and increases in the requirements of owners of riding horses and small animals. Most of the witnesses consulted agreed to this figure of 220 ; but others, including the Royal College of Veterinary Surgeons, hesitated to do so, partly because they feared that the Government's present policy would not be carried on and partly because they feared that the unqualified practitioner might reduce the work of qualified men.

The Committee does not think that qualified men from Eire will come over to practise in Great Britain in sufficient numbers to affect the demand, and it recalls that most of the veterinarians practising in British Colonies are trained in Great Britain. This Colonial demand will, the Committee thinks, increase rather than diminish, because, as the control of the major diseases of livestock in the Colonies, which has occupied and is now occupying the attention of Colonial veterinarians, becomes established, other diseases which have been masked by these major diseases will need attention, and these are likely to require more men for their control. Because the progress of pastoral Colonial peoples depends largely upon adequate production of dairy and other livestock products, this branch of the work of the veterinary profession is likely to become increasingly important. The Committee's recommendations are therefore framed on the estimate of 220 veterinarians a year for ten years, and it sees no reason at all why this demand should fall to 150. It is suggested, in fact, that the figure 220 may prove to be too low. In support of this view, the report includes a table based on information supplied by the Allied Postwar Requirements Bureau, which shows that the number of veterinarians per million of the larger domestic animals is $\mathbf{9 4 . 4}$ in Great Britain, 98.8 in France, 123 in Norway, 140 in the Netherlands, 14 ? in Denmark, 149 in Germany, and 247.8 in Switzer. land. In the United States the corresponding figur is only 60 , but much farm stock in that country $i_{\text {}}$ kept under ranch conditions; further, reforms in veterinary education and increases in the numbers of veterinarians are now being urged and planned. The table indicates that the number of veterinarians per million of the population in the United States is twice as great (109) as it is in Great Britain $(50 \cdot 2)$ and the United States figure compares favourably with the corresponding figures cited for other European countries.

The rest of the report deals with the number and location of the veterinary schools, the functions of the Royal College of Veterinary Surgeons, the licence to practise, the association of veterinary training with the universities of Great Britain and with finance. The training of 220 veterinarians a year cannot, the Committee decides, be accomplished by the expansion of the existing four veterinary schools at London, Edinburgh, Liverpool and Glasgow. Eire and its veterinary school at Dublin are not considered. The ideal size for a veterinary unit is, the Committee concludes, one which will provide thirty graduates a year, and all the universities consulted agreed to this figure. The Liverpool school cannot expand beyond this, which it now achieves. The existing Glasgow College is inadequate. If thirty men a year are allocated to this school, which would become an integral part of the University of Glasgow, the London and Edinburgh schools would have to produce 160 graduates a year between them, which would mean about 1,000 students in these two schools combined. The Committee considers that this is too many. Complaints of overcrowding are already universal, and the Committee agrees that they are well founded. It suggests that the number of students at the London school should be limited to 325, and at the Edinburgh school to 275, and that the field stations attached to each school, recommended in the Committee's first report, and again emphasized in this second one, should relieve the pressure on these schools by providing most of the clinical training. London and Edinburgh should then be able to supply a hundred veterinarians a year.

Provision would then be required for sixty more, and the Committee proposes the establishment of two new colleges, one at Bristol and one at Cambridge. There would thus be six veterinary schools in Great Britain, each with a field station and preferably with a hospital for large animals. Veterinary students would receive farm pupilage for not less than six months in the care of normal livestock and also would spend at least six months with a practising veterinarian. There would be provision, in the normal estimates of each school, for continuous research, and bursaries and graduate scholarships would be provided. It is rightly emphasized that these should be of sufficient value to enable the recipients to 
take a full part in university or college life. Private endowment of veterinary education and the work of the Veterinary Educational Trust are also commended.

The reasons for the selection of Cambridge and Bristol as the sites of these two new centres need not be set out in detail here. At Cambridge the veterinarian would be in contact with experts in all the branches of science and the arts, and also with the various agricultural institutes there. At Bristol a veterinary college would, the Committee thinks, be well placed to serve the area south and west of a line drawn between Aberystwyth, Worcester, Swindon and Weymouth. A veterinary school in Wales was considered and urged by the Welsh Council of Agriculture ; but the Committee felt that each veterinary school should be in close touch with a large and important grazing district, should be able to establish a field station within easy reach, should have suitable accommodation for the pre-clinical years, should be in a centre possessing good medical and agricultural schools and should be remote from other veterinary schools. Although Cardiff and Aberystwyth both fulfil some of these requirements, the Committee concluded that Bristol could best serve south-western England and central and south Wales, while Liverpool could serve north Wales. Not everyone will agree with the Committee's rejection of the claims of Wales to its own veterinary school. The Committee says that, if the demands of the future require more centres, the claims of Wales will have to be considered. Many will think that they should be satisfied now, one reason being that Wales, like Scotland, presents rather special veterinary and agricultural problems which should be studied at such a Welsh centre.

The requirements detailed by the Committee for the choice of sites for veterinary schools are, however, intimately bound up with one of the most important of the Committee's recommendations. This is the Committee's view that the best possible training for the veterinarian can only be obtained by persuading the universities to undertake the responsibility for it. This recommendation is an extension of the recommendation in the Committee's first report that there should be a close connexion between veterinary education and the universities. It involves far-reaching changes, some of which are not, as recent correspondence in The Veterinary Record shows, acceptable to many members of the veterinary profession. The Committee's ideal is that veterinary schools should become parts of universities in the same sense as medical schools. This is already so in Liverpool. The Committee is satisfied that the following conditions should apply to all university schools of veterinary medicine. The necessary money should be provided by the State; the degree in veterinary medicine given by the university should become a registrable qualification; and the university should have a measure of control over the instruction given, and over the university examinations held, similar to that "generally exercised in the case of medical degrees".

While the Committee "favours the idea" that the universities concerned should establish new faculties of veterinary medicine, it does not make any definite recommendation on this point, because "so much depends on the conditions prevailing at each individual University". Many will regret the lack of decision in this matter. If veterinary education is to be undertaken by the universities at all, it must certainly be given, from the very beginning, an equal status with medicine, agriculture or any other university study which constitutes a faculty. It would be emphatically insufficient, for example, to create a department of veterinary medicine within, or subordinate to, any other faculty. The veterinary profession can only be given its legitimate place in any university by the creation of a faculty of veterinary medicine of full status, the affairs of which would be governed, like those of other faculties, by the veterinary staff in co-operation with other university teaching officers. In no other way would it be possible for the veterinary teacher as well as the veterinary student to take their full part in university life and to experience its full effects. By administering and teaching in a full veterinary faculty the veterinarian would, moreover, be in the best position to introduce effectively into the university those new problems and new spheres of work which could be such valuable additions to university studies. This contribution which veterinarians can bring to the universities is too easily overlooked. It has a very real national importance and no university can afford to neglect it.

While it is clear that the Committee desires the creation of faculties of veterinary medicine of independent status, it is no less clear that it emphasizes its further recommendation that university degrees in veterinary medicine shall be registrable qualifications. There is a lack of clarity in the report on this point which requires elucidation. The Committee recom. mends that university degrees in veterinary medicine shall be registrable by the Royal College of Veterinary Surgeons and by that College alone; and it also recommends that the Royal College shall continue its own examinations and shall continue to grant the diploma of M.R.C.V.S. on the results of these examinations, which would presumably be held only in those existing veterinary colleges which do not, for one reason or another, become constituent parts of universities. There would thus be two possible veterinary qualifications-a university degree in veterinary medicine, and the diploma of M.R.C.V.S. granted only by the Royal College of Veterinary Surgeons on the results of its own examinations. The Committee's recommendation is that the Royal College of Veterinary Surgeons should be the only body legally empowered to register either or both of these qualifications, and to grant a licence to practise veterinary medicine. The recipient of a university degree in veterinary medicine would therefore have to register with the Royal College of Veterinary Surgeons, just as the recipient of a university degree in medicine or surgery must place his name on the Medical Register before he can practise.

It would further be necessary, the Committee thinks, to create a body independent of the univer- 
sities which would be empowered to secure a minimum standard of qualification to practise veterinary medicine. It is proposed that the Council of the Royal College of Veterinary Surgeons should be given this power. The College would therefore control both the education of veterinarians and their licence to practise. Its constitution would be widened and it would be given powers similar to those granted to the General Medical Council by the Medical Acts of 1858 and 1886, the relevant portions of which are quoted in Appendix VI of the Committee's report. These Acts would empower the new Council of the Royal College of Veterinary Surgeons to appoint inspectors who would have the right to attend, and report on, the examinations held at any centre, and to ask for details of the courses of instruction provided. If either these courses or the examinations were not considered adequate, the Council of the College could report to the Privy Council, which could declare that such courses or examinations should not qualify for a registrable qualification in veterinary medicine. The new Council's authority would also extend to veterinary schools which are not parts of universities.

It would thus seem that the Royal College of Veterinary Surgeons would retain all reasonable control of the profession. Some veterinarians have said that the proposals of the Committee involve the relinquishment by the College of the sole control over the educational standards of the veterinary profession in Great Britain which it now exercises; but other veterinarians have replied to this that, in actual fact, the College does not at present exercise this control. It controls only the examinations, and has no control over the instruction given in the existing veterinary colleges, nor any over the time which is given to the study of individual subjects in them.

Objections have also been raised to the Committee's proposal to bring into the new Council of the Royal College of Veterinary Surgeons certain persons who are not veterinarians. Here it should be emphasized that precisely four, and four only, of the thirtythree members of the new Council need not be veterinarians. The Committee does not, let it be noted, say that these four must not be veterinarians. They are to be appointed by the Crown; and no doubt the Crown will appoint, if not veterinarians, then men who have shown themselves to be sympathetic to the veterinary profession or to have contacts with it which have given them an understanding of its problems and aspirations. The profession itself is, moreover, to be given the majority vote in the new Council; for seventeen of the thirty-three members would have to be freely elected by the profession precisely as the whole Council is now elected. The other twelve would be nominated by the universities and the veterinary colleges which would teach and grant the single registrable qualification. Twenty-nine members of the new Council would be veterinarians and a majority of the whole Council would have to be freely elected by the profession. If such a Council could not safeguard every vital interest of the profession, then the profession itself would alone be to blame. It is worth remember. ing, also, that the report of this Committee is not a series of edicts from which there is no appeal. It is a number of recommendations based on evidence taken from veterinarians themselves and from teachers of veterinarians, as well as from educational experts all over Great Britain ; and these recommendations are put forward for calm discussion in Parlia. ment and elsewhere.

The Committee was specifically asked to devise plans for the best possible training for the veterinarian, having regard to the anticipated expansion of the profession, and it believes that university training alone can effect this. There will be few who will not agree with this view. Many veterinarians are already taking university degrees of one kind or another as well as their veterinary training. This means, as the Committee points out, that they have to take two or more courses, with the corresponding examinations, and must thus waste much time. One result, however, is that increasing numbers of veterinarians are learning by experience the advantages of university life, and most of them will be strongly in favour of the Committee's insistence on university education. They are by no means uncriti. cal of the universities. No progressive mind is. Most people who have given any thought to the universities desire reforms of one kind or another. It is, in fact, one of the most valuable results of university education that it teaches men the folly and sterility of stagnation and satisfaction.

Veterinarians, moreover, like all men of science, must, as members of scientific research teams, experience that cultural effect of practical scientific work which teaches men to sink their own desires and differences and to pull their full weight for the achievement of a common aim. They may think that this is enough; or even that it is better than a university education. But surely the best university education is essentially an extension of this spirit, not only into the non-scientific world, but also into the social unit, the nation and finally the world. Men experiencing it cannot fail to become, as the Com. mittee suggests, better men. "Universities," wrote Dr. John Murray in the Sunday Times (May 7, 1944), "can only vivify each new generation by witnessing to the common body of culture"; and he rightly pointed out that, in an age of specialism, we must compensate for specialism by common study carried out in a community. The logie of events, he writes, is making the universities the meeting ground of the youth of Britain and of every other land ; it is making them "agencies of mutual understanding, organs of a world spirit of amity and conciliation". The veterinarian should be included in this Parliament of Youth, for his work has a vital place in the development of civilization. Dr. Murray thinks that the future of the universities may lie, not in great cities, but in small ones, in old and historic places, in the countryside where there is continuity with the past, in "places such as Oxford was and Cambridge still is". It is not irrelevant to add to these the Exeter from which Dr. Murray writes, and where he presides over an educational community which draws to its 
happy atmosphere students from all over the world. It seems a pity that this College, situated as it is in the middle of one of the greatest agricultural districts of England, cannot be given a part in the training of the veterinarians whose services that district must have. Would it not be possible, for example, to link it with the new centre at Bristol in some form or other?

Another aspect of the Committee's report remains for comment. The Committee adopts, on more than one page of its report, what some will consider to be an insufficiently firm attitude to the universities. The Committee, for example, "strongly urges" the universities giving registrable veterinary qualifications to include practising veterinarians among their external examiners, and to consult the Council of the Royal College of Veterinary Surgeons when they are appointing them. The College, of course, insists on the inclusion of veterinary practitioners as examiners in the clinical subjects, and many will think that the universities should be plainly told that they must establish a rule so obviously essential. Elsewhere the Committee says that it is "encouraged to believe" that one of the universities concerned "might be prepared to establish a School of Veterinary Medicine" such as the Committee proposes and to grant a degree in veterinary medicine, subject to the conditions which have been mentioned above. Of another university the report says that the Com. mittee understands "that the university would not be adverse in principle" to its proposals. The position at another university centre is described as "exceptional". The remaining two universities have, however, expressed their willingness to carry out the Committee's proposals. There would thus appear to be a need for a reminder that all universities, jealous as they must be of their independence, also have a public duty in a matter of such national importance as this.

There is a spirit abroad among the young men of to-day which will not brook anything but a progressive spirit among its educational leaders. Certainly the veterinary profession has demonstrated that there are among its leaders men who are progressive, able and mellowed by a culture which extends beyond their own science and art. They have proved them. selves to be wise administrators as well as first-class practitioners of their profession. They are, like the medical men, determined to uphold their just rights, but they are not willing to do this obstinately or to refuse that patient but firm conciliation which has always been the mark of the ablest men throughout the centuries. They are aware, like the leaders of the medical and other professions, that conciliation, reasonableness and wise judgment are required of all responsible men at a time when the whole world is being reconstructed on a basis of good-will and the best possible service by all for the greatest good of the whole. It is not to be expected that the authorities of British universities will be any less conscious of their national responsibilities, nor any less willing to reach a speedy and just solution of the relatively minor difficulties presented by the recommendations of this report.

\section{THE SUPREMACY OF REASON}

\section{'42 to ' 44}

A Contemporary Memoir upon Human Behaviour during the Crisis of the World Revolution. By H. G. Wells. Pp. 212. (London : Martin Secker and Warburg, Ltd., 1944.) 42s. net.

AR. WELLS is indefatigable, and advancing 1 years seem in no way to diminish the output or readiness of his pen. This "Contemporary Memoir" consists of two parts with three appendixes, the sequence and relation of which are by no means so apparent as they might be. Even the sedulity which Mr. Wells demands of his reader at the point of his preface might well fail to reveal a common theme or dominant motif. Moreover, only part of the book is new-how much even one with the full range of Mr. Wells's more recent writings in front of him might not be able to say with any certainty-and the high price will scarcely dispose a reader to excuse the compilation of so much material from previous writings without at least some biographical reference. Evasiveness or indefiniteness on this point is not con. fined to his own writings, for in this matter Mr. Wells is thoroughly inconsistent. Sometimes he provides a complete reference to a book that has interested him, but he quotes several pages from what is presumably General Smuts's address to the South African Institute of Race Relations in January 1942 without bothering to insert the line that would help a reader who wished to confirm his quotation or consult the full text to trace the New Africa Pamphlet No. 2, "The Basis of Trusteeship", in which that speech has been printed.

What might be overlooked in the journalist can scarcely be condoned in a more serious study that claims to be an autobiography of ideas, in some ways continuing, supplementing and expanding Mr. Wells's earlier "Experiment in Autobiography". Moreover, as giving the mature views of Mr. Wells as philosopher summing up his position after a life-time of work and study, the book might be placed in the philosophical class. That claim may indeed be contested, for if Mr. Wells is a true philosopher, can bis irrepressible vitality and imagination ever allow him to be mature? There are serious passages in the book and flashes of the brilliant and imaginative writing we expect from him. For the most part, it is journalism -inconsistent, sometimes irrelevant, even dogmatic or bullying, but always Mr. Wells, as when the kindly aria in praise of Beatrice Webb breaks the thundering notes of the grand oratorio of the private -or is it the public?-hates of $\mathrm{Mr}$. Wells which occupy so much of the second part of the book. Mr. Wells tries hard at times; but his comments are seldom as detached as they purport to be. They are usually lively, often intemperate-as he readily admits-and sometimes stimulating and suggestive, which after all is one reason why this author is read.

In the first part of the book, Mr. Wells discusses the reasons for the recrudescence of eruelty in this modern world, and ends on the optimistic note that the idea of a new world based on a universally valid declaration of equal human rights is now making headway against every device of its antagonists. In this part Mr. Wells is happily irrelevant, and in view of the warning to the reader in his preface, one may well wonder whether he has not started off by deliberately making his argument obscure, or whether in some Puckish mood Mr. Wells has not written 